\title{
The Embedding of Meta-tetra(Hydroxyphenyl)-Chlorin into Silica Nanoparticle Platforms for Photodynamic Therapy and Their Singlet Oxygen Production and pH-dependent Optical Properties
}

\author{
Fei Yan and Raoul Kopelman* \\ Department of Chemistry, University of Michigan, Ann Arbor, MI
}

Received 1 May 2003; accepted 18 September 2003

\begin{abstract}
This study relates to nanoparticle (NP) platforms that attach to tumor cells externally and only deliver singlet oxygen for photodynamic therapy (PDT) while conserving the embedded photosensitizers (PS). As a model, we demonstrate the successful embedding of the PS meta-tetra(hydroxyphenyl)chlorin ( $m$-THPC) in NP that are based on a sol-gel silica matrix and also show its positive effect on the singlet oxygen production. The embedding of $m$-THPC inside silica NP is accomplished by a modified Stöber sol-gel process, in which (3-aminopropyl)-triethoxysilane is introduced during the reaction. Singlet oxygen delivery by the targetable photodynamic NP exceeds that from free PS molecules. In the physiological $\mathrm{pH}$ range, there is no significant $\mathrm{pH}$-induced decrease in the fluorescence of $m$-THPC embedded in silica NP, which might otherwise affect the efficiency of PDT.
\end{abstract}

\section{INTRODUCTION}

Photodynamic Therapy (PDT), also called photochemotherapy, is a promising treatment for a variety of oncological, cardiovascular, dermatological and ophthalmic diseases (1-5). Efforts are currently underway to produce PDT nanoparticles (NP) for targeted delivery (6-8). An ideal PDT photosensitizer (PS) should meet several criteria, which include chemical purity; tumor selectivity; fast accumulation in target tissues and rapid clearance; activation at wavelengths that penetrate deep into tissues; high potential of lightactivated tissue damage and no dark toxicity (6). Unfortunately the majority of PDT sensitizers only partially meet these criteria.

One of the problems limiting the use of many PS is the difficulty in preparing pharmaceutical formulations that enable their administration (7). Because of their low water solubility, the hydrophobic PS cannot be simply injected intravenously. This also complicates

TPosted on the website on 26 October 2003

*To whom correspondence should be addressed at: Department of Chemistry, University of Michigan, 930 North University Avenue, Ann Arbor, MI 48109-1055, USA. Fax: 1734-936-2778; e-mail: kopelman@umich.edu

Abbreviations: ADPA, anthracene-9, 10-dipropionic acid, disodium salt; $\mathrm{HpD}$, hematoporphyrin derivative; $m$-THPC, meta-tetra(hydroxyphenyl)chlorin; NP, nanoparticles; PBS, phosphate-buffered saline; PDT, photodynamic therapy; PS, photosensitizers; SEM, scanning electron microscopy.

(C) 2003 American Society for Photobiology $0031-8655 / 03 \quad \$ 5.00+0.00$ the attachment of targeting agents such as antibodies (9). Different strategies, including polymer-PS conjugation or encapsulation of the drug in colloidal carriers such as oil dispersions, liposomes and polymeric particles, have been investigated (7). Although these colloidal carriers tend to accumulate selectively in tumor tissues, they are rapidly taken up by the mononuclear phagocytic system. In contrast to other NP, which deliver PS to the inside of the cells $(7,8)$, the recently used NP platforms attach themselves to the outside of the cell and deliver singlet oxygen from there $(10,11)$. The silica NP described here have been designed for such a purpose, i.e. not to deliver dye molecules but only singlet oxygen. Such a nanoplatform is a modular system that contains thousands to millions of photodynamic molecules, bringing them as a single, massconserved nondepleting synergistic unit to the outside of a tumor cell. The concentrated packaging of these components provides not only inherent signal amplification for localization and signature detection but also a coherent, critical mass of destructive power for intervention, which can be coupled with other included sensitizers and probes for enhanced therapeutic efficacy. The relatively longlived particles of the dynamic nanoplatforms are noninvasively injected into the organism. Hydrophilic coatings provide reduced uptake by the reticuloendothelial system, resulting in both increased delivery of the DNP to tumor sites and reduced toxicity to other body tissues. Specific molecular targeting functional groups can be attached for localized binding to or uptake by the tumor cells (or both), as well as for passage through the blood-brain barrier when appropriate $(12,13)$.

First-generation PS such as Photofrin ${ }^{\circledR}$ I, hematoporphyrin derivative $(\mathrm{HpD})$ and Photofrin ${ }^{\circledR}$ II suffer from several drawbacks $(14,15)$, which are: (1) They show a poor selectivity in terms of tumor tissue-normal tissue ratios (PDT selectivity index) because of their high degree of chemical heterogeneity. Oligomeric components of Photofrins exhibit the greatest hydrophobicity and hence ability to cross cell membranes, but they have short-lived triplet states and are inefficient generators of the cytotoxic species singlet oxygen (16). (2) The stability of Photofrins in tissues is questionable. Ester bonds linking hematoporphyrin units are susceptible to esterase-catalyzed hydrolysis in body fluids; moreover, the noncovalent aggregates can be split into monomers in subcellular loci having a low dielectric constant, such as the lipid regions of the cytoplasmic, mitochondrial and Iysosomal membranes (17). These processes would lead to a population of porphyrins characterized by widely different photosensitizing activities. (3) Their low extinction coefficients, around $630 \mathrm{~nm}$, lower the probability of their photoexcitation, furthermore, the 


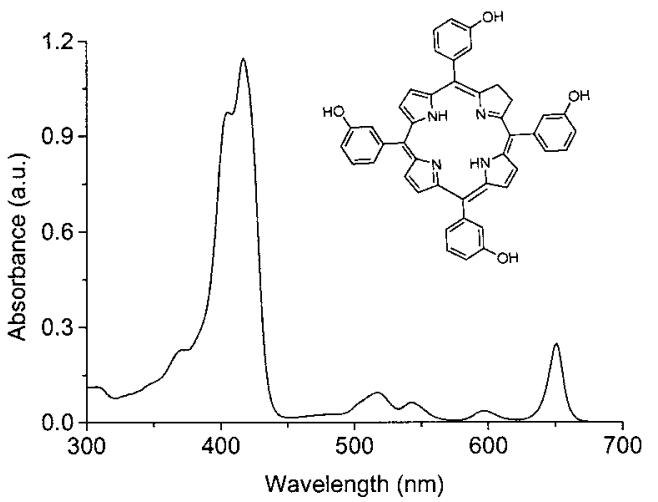

Figure 1. Absorption spectra from $m$-THPC solution $(7.5 \mu M)$ in ethanol, inset: chemical structure of $m$-THPC

adsorption maximum is at a relatively short wavelength $(630 \mathrm{~nm})$ leading to poor tissue penetration of light, thus requiring the administration of relatively large amounts of dye $\left(2-5 \mathrm{mg} \mathrm{kg}^{-1}\right.$ body weight) to obtain a satisfactory phototherapeutic response. Because some components of Photofrins are retained in amounts as large as several micrograms per gram of tissue by liver and spleen (17), the possible onset of long-term toxic effects must be taken into consideration. (4) They present a high accumulation rate in skin, which induces a prolonged cutaneous light ultrasensibility lasting up to 6-8 weeks after PDT treatment. During this posttreatment period, patients have to stay out of sunlight to avoid a severe sunburn reaction. Second-generation PS with improved efficiency and fewer side effects have now been developed, and meta-tetra(3hydroxyphenyl)-chlorin ( $m$-THPC), currently under Phase II clinical trial, shows promising results. The $m$-THPC is superior to HpD and Photofrin II in several ways $(18,19)$ : (1) it is a single component of $98 \%$ purity; (2) it has an absorption coefficient at 652 $\mathrm{nm}$ that is larger than that of HPD and Photofrin II by one order of magnitude (Fig. 1); (3) it has high phototoxicity and a large fluorescence quantum yield; and (4) it induces somewhat shorter cutaneous photosensitivity.

As is well known, there is strong evidence for the involvement of singlet oxygen, a powerful oxidant, in photosensitized oxidations, in photodynamic inactivation of viruses and cells, in phototherapy for cancer and in photodegradation of polymers. Much of the current interest in the chemical reactions of singlet oxygen stems from its potential as a photochemotherapeutic agent (20-25). Lower extracellular $\mathrm{pH}$ in tumors as compared with normal tissues has also been proposed to be a factor contributing to the tumor selective uptake of several PS $(21,26)$. Protonation or deprotonation of ionizable groups within porphyrin-type molecules such as $m$-THPC results in modification of PDT drug physicochemical properties such as lipophilicity, net charge and state of aggregation. All these properties are assumed to be involved in interactions of the PS with biological objects (27). In this article, we compare the spectroscopic properties of and the $\mathrm{pH}$ influence on free $m$-THPC with those of $m$-THPC embedded in a silicon-based DNP matrix. The emphasis is on the comparison of the singlet oxygen production by free PS molecules with that of PS embedded in NP.

\section{MATERIALS AND METHODS}

Chemicals. The $m$-THPC was obtained as a lyophilized powder from Biolitec Pharma Ltd. (Edinburgh, UK). A solution was prepared in ethanol- water $(50: 50 \mathrm{vol} / \mathrm{vol})$ just before use. Other chemicals were from SigmaAldrich, St. Louis, MO. A stock solution of phosphate-buffered saline (PBS, $\mathrm{pH}$ 7.4) was made in water, and a series of PBS-ethanol (50:50 vol $/ \mathrm{vol})$ solutions with different $\mathrm{pH}$ values (i.e. 3.44, 6.91, 7.37, 8.30, 10.18, 11.65) were prepared. The $\mathrm{pH}$ value of PBS-ethanol (50:50 vol/vol) solution was adjusted using a $\mathrm{pH}$ meter (Corning ${ }^{\circledR}$, Model 140$)$ by adding $\mathrm{HCl}(0.1019$ $N$ ) or $\mathrm{NaOH}(0.1004 N)$ volumetric standards from Aldrich. Approximately $0.40 \mathrm{~m} M$ solutions of $m$-THPC were prepared in pure ethanol. Aliquots of $100 \mu \mathrm{L}$ of these solutions or $2 \mathrm{mg}$ of silica NP embedded with $m$-THPC were added to $2 \mathrm{~mL}$ of PBS-ethanol solutions of different $\mathrm{pH}$.

Preparation of silica NP embedded with m-THPC. The $m$-THPC embedding steps inside silica NP are as follows: after mixing (3aminopropyl) triethoxysilane $(99 \%, 0.2 \mathrm{~mL})$ with ammonium hydroxide (30\% wt of ammonia, $6 \mathrm{~mL}$ ) and methanol $(99.9 \%, 24 \mathrm{~mL}$ ), tetramethylorthosilicate $(99.9 \%, 0.2 \mathrm{~mL})$ was added drop by drop to initiate the hydrolysis reaction. The solution was then stirred vigorously at room temperature for $2 \mathrm{~h}$ before the reaction was stopped. After the reaction was stopped, a liberal amount of ethanol was then added to the reaction solution and the mixture was transferred to an Amicon ultrafiltration cell (Millipore Corp., Bedford, MA). A $100 \mathrm{kDa}$ membrane was used to separate the silica particles from the unreacted monomers and ammonia, under a pressure of $10 \mathrm{psi}$. The particles were further rinsed with at least $500 \mathrm{~mL}$ distilled water and $200 \mathrm{~mL}$ ethanol to ensure that all unreacted reactants had been removed from the silica particles. The silica particle suspension was then passed through a suction filtration system (Fisher, Pittsburgh, PA) with a $20 \mathrm{~nm}$ filter membrane to collect the particles that were then dried to yield a final product of silica NP embedded with $m$-THPC.

Scanning electron microscopy imaging. To prepare the samples for scanning electron microscopy (SEM) studies, dried silica NP were dispersed in water and the resultant suspensions were sonicated for 1-2 $\mathrm{h}$. Then a drop of the silica particle suspension was placed on a piece of micro glass slide (Arthur H. Thomas Co., Philadelphia, PA) attached to a metal grid coated with carbon film and dried gradually at room temperature. The sample was then sputter coated with gold and observed using a Philips XL30FEG scanning electron microscope to assess the particle size and shape.

Spectroscopic characterization. A UV160U UV-visible recording spectrophotometer (Shimadzu, Columbia, MD) was used for absorption measurements. Fluorescence measurements were obtained from FluoroMax-3 Spectrofluorometer (Jobin Yvon/SPEX Division, Instruments S. A. Inc., Edison, NJ). All fluoroMax-3 functions are under total control of DataMax spectroscopy software. The measurements were taken at room temperature. During the irradiation, a small magnetic bar was kept stirring in position 6 to ensure a better suspension.

Anthracene-9, 10-dipropionic acid, disodium salt test for ${ }^{1} \mathrm{O}_{2}$ production. Measurements were carried out in a plastic cuvette $(10 \times 10 \mathrm{~mm})$ according to a procedure described previously (22). Briefly, a $2 \mathrm{~mL}$ $m$-THPC dye solution $(0.18 \mu M)$ in water-ethanol $(1: 1 \mathrm{vol} / \mathrm{vol})$ or NP embedded with $m$-THPC dye suspension $(1 \mathrm{mg} / \mathrm{mL})$ in water-ethanol $(1: 1$ $\mathrm{vol} / \mathrm{vol})$ that contains $0.18 \mu \mathrm{M} \mathrm{m}$-THPC, and $200 \mu \mathrm{L}$ anthracene-9, 10 dipropionic acid, disodium salt (ADPA) $(10 \mu M)$ was placed in a cuvette while mixing with a magnetic stirring bar at moderate speed. The amount of $m$-THPC present in the NP was evaluated by its excitation and emission intensities and calculated from a calibration curve generated from free $m$-THPC standard solutions. The fluorescence emission of ADPA when excited at $376 \mathrm{~nm}$ was recorded, and the solution was then irradiated at 650 $\mathrm{nm}$ using a $150 \mathrm{~W}$ ozone-free xenon-arc lamp (Jobin Yvon), with a slit width of $10 \mathrm{~nm}$, for various time periods (i.e. $0,5,15$ and $35 \mathrm{~min}$ ).

\section{RESULTS AND DISCUSSION}

\section{Preparation of silica NP embedded with $m$-THPC}

The initial endeavor of embedding $m$-THPC using the conventional sol-gel silica preparation, in which no (3-aminopropyl) triethoxysilane was involved in the reaction, was unsuccessful. This was evidenced by colorless powders obtained after the product was rinsed with ethanol and water. It turned out that the addition of an amine derivative of oxysilane helped to keep some of the $m$-THPC inside the matrix, which is probably because of the increased amount of hydrogen bonding between $m$-THPC and amine groups on (3-aminopropyl) triethoxysilane. A typical SEM image of silica 


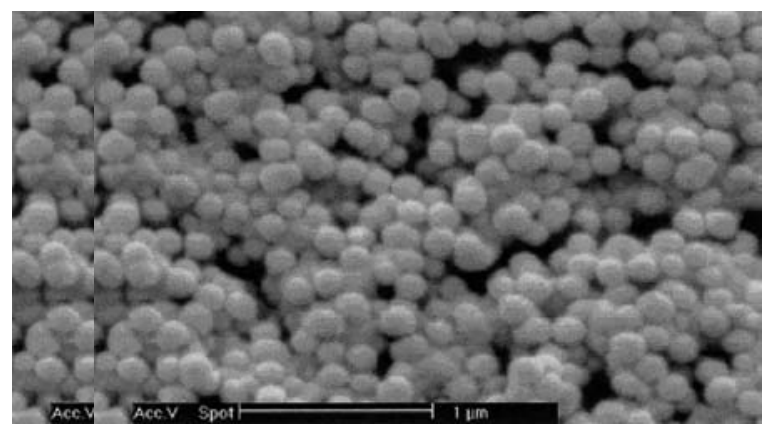

Figure 2. SEM image of $m$-THPC-embedded silica nanoparticles. The average diameter of the particles is $180 \mathrm{~nm}$. Bar $=1 \mu \mathrm{m}$.

NP embedded with $m$-THPC is shown in Fig. 2. The average diameter of this batch of NP was $180 \mathrm{~nm}$. The final size of the silica NP is important because the lifetime of ${ }^{1} \mathrm{O}_{2}$ in aqueous media is in the $\mu$ s regime, during which interval it can diffuse over a mean radial distances of at least $100 \mathrm{~nm}$, using $\mathrm{F}=\sqrt{6 \mathrm{D} \tau}$, where $\mathrm{F}$ is the mean radial displacement in time $\tau(=1 \mu \mathrm{s})$ with a diffusion coefficient, D, $2 \times 10^{-5} \mathrm{~cm}^{2} \mathrm{~s}^{-1}(23,24)$. As can be seen in Fig. 2, the particles are spherical, and the polydispersity is small. Excitation and emission spectra of a free $m$-THPC dye solution dissolved in ethanol-water (50:50 vol/vol) and a suspension of $\mathrm{m}$ THPC embedded in silica NP $(1 \mathrm{mg} / \mathrm{mL})$ in ethanol-water (50:50 vol/vol) are shown in Fig. 3. There is good spectral correspondence between the free dye solution and the NP suspension. The choice of ethanol-water mixture as the solvent was reported by several groups for the spectroscopic studies of $m$-THPC because $m$-THPC is insoluble in water, and ethanol solutions closely resemble the hydrophobic in vivo microenvironment $(18,21)$.

\section{Singlet oxygen detection by ADPA}

Because of the ease with which ADPA is converted to an endoperoxide by singlet oxygen, this reaction has been used as a test for the presence of singlet oxygen (24). The following discussion is tailored specifically to the system we are dealing with, in which a substrate (i.e. ADPA) and a sensitizer (i.e. $m$-THPC) are irradiated together in a solution, all of the following processes of singlet oxygen may take place (20-23):

$$
\begin{aligned}
& { }^{*} m \text {-THPC }+{ }^{3} \mathrm{O}_{2} \rightarrow m \text {-THPC }+{ }^{1} \mathrm{O}_{2}^{*} \quad k \\
& \text { ADPA }+{ }^{1} \mathrm{O}_{2}^{*} \rightarrow \text { ADPA endoperoxide } k_{\mathrm{c}} \\
& \mathrm{ADPA}+{ }^{1} \mathrm{O}_{2}^{*} \rightarrow \text { ADPA }+{ }^{3} \mathrm{O}_{2} \quad k_{\mathrm{p}} \\
& { }^{1} \mathrm{O}_{2}^{*} \rightarrow{ }^{3} \mathrm{O}_{2}
\end{aligned}
$$

Where $k$ is the rate constant for the quenching of excited $m$-THPC by triplet oxygen to produce singlet oxygen, $k_{\mathrm{c}}$ and $k_{\mathrm{p}}$ are the rate constants of chemical and physical quenching of singlet oxygen in the presence of ADPA, respectively, and $k_{\mathrm{d}}$ is the rate constant for the decay of singlet oxygen to its ground state.

The loss of ADPA in reaction with ${ }^{1} \mathrm{O}_{2}^{*}$ is then given by

$$
\begin{aligned}
-\mathrm{d}[\mathrm{ADPA}] / \mathrm{dt} & =k_{\mathrm{c}}[\mathrm{ADPA}]\left[{ }^{1} \mathrm{O}_{2}^{*}\right] \\
& =k_{\mathrm{c}}[\mathrm{ADPA}]\left[{ }^{1} \mathrm{O}_{2}^{*}\right]_{0} \mathrm{e}^{-\left(k_{\mathrm{d}}+\left(k_{\mathrm{p}}+k_{\mathrm{c}}\right)[\mathrm{ADPA}]\right) \mathrm{t}} \\
& =k_{\mathrm{c}}[\mathrm{ADPA}]\left[{ }^{1} \mathrm{O}_{2}^{*}\right]_{0} \mathrm{e}^{-k^{\prime} \mathrm{t}}
\end{aligned}
$$

where $k^{\prime}=k_{\mathrm{d}}+\left(k_{\mathrm{p}}+k_{\mathrm{c}}\right)$ [ADPA], and $\left[{ }^{1} \mathrm{O}_{2}^{*}\right]_{0}$ is the ${ }^{1} \mathrm{O}_{2}^{*}$ concentration before any appreciable loss in steps (2)-(4). A rough

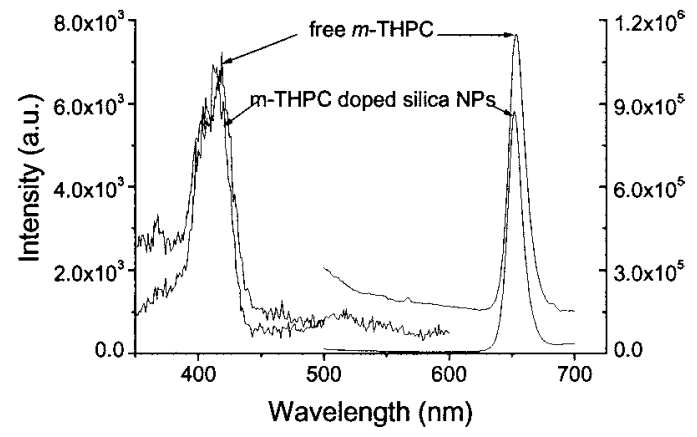

Figure 3. Excitation and emission spectra of: (A) Free $m$-THPC $(0.18 \mu M)$ dissolved in ethanol-water (50:50 vol/vol), and (B) $m$-THPC embedded silica nanoparticles $(1 \mathrm{mg} / \mathrm{mL})$ suspended in ethanol-water $(50: 50 \mathrm{vol} / \mathrm{vol})$ containing $0.18 \mu \mathrm{M} \mathrm{m}$-THPC. Left $y$-axis is excitation intensity (arbitrary units), and right y-axis is emission intensity (arbitrary units).

estimation of the rate constant for the chemical quenching of ADPA by ${ }^{1} \mathrm{O}_{2}^{*}$ could be obtained using a simplified equation where only reaction (2) is considered, provided that the reduction of fluorescence intensity is caused mainly by this step.

$$
[\mathrm{ADPA}]_{\mathrm{t}}=[\mathrm{ADPA}]_{0} \exp \left(k_{\mathrm{c}}\left[{ }^{1} \mathrm{O}_{2}^{*}\right]_{0} \mathrm{t}\right)
$$

Therefore, the relative rate constant $k_{\mathrm{c}}$ can be extrapolated by a computer-fitted exponential equation, using the experimental data.

\section{Time based measurements for the mixture of $m$-THPC embedded in amine-functionalized silica NP with ADPA after irradiation at $650 \mathrm{~nm}$ for different time intervals}

The fluorescent intensity of ADPA decreased as the irradiation time increased, which indicates that the amount of singlet oxygen production increased when silica NP embedded with $m$-THPC were irradiated at $650 \mathrm{~nm}$ for a longer time (data shown in Fig. 4). The exact reaction rate constant with ADPA for free $m$-THPC and $m$-THPC embedded in silica NP is shown to be $2.7 \times 10^{8} M^{-1} \mathrm{~s}^{-1}$ and $4.8 \times 10^{8} M^{-1} \mathrm{~s}^{-1}$, respectively. The $k_{\mathrm{c}}$ values obtained by us are greater but still in the same magnitude as the total rate constant $\left(1 \times 10^{8} \mathrm{M}^{-1} \mathrm{~s}^{-1}\right)$ reported for a similar aqueous system, in which a PS tris (2,2' -bipyridine) ruthenium (II) ion was used to generate singlet oxygen (28), therefore, it is reasonable that physical quenching can be indeed ruled out as a major contributor in the total quenching of ADPA in our case, this is also suggested by other group's observation, in which ADPA was believed to be mainly bleached by singlet oxygen to its corresponding endoperoxide (29). The values obtained for the rate of consumption of ADPA when $m$-THPC is embedded in the silica NP, as compared with the free $m$-THPC dye, cannot be directly translated into differences in terms of the quantum yield of ${ }^{1} \mathrm{O}_{2}$ production, because the matrix may affect the rate constant in several ways that were not evaluated, i.e. (1) the matrix may quench the ${ }^{1} \mathrm{O}_{2}$ produced; (2) the matrix may increase the local concentration of ${ }^{3} \mathrm{O}_{2}$; and (3) the matrix may affect the rate of physical quenching, as described previously (22). The important point is that, by most expectations, factor (i) (quenching) would reduce the singlet oxygen delivery from the NP, compared with that from the free dye; however, the singlet oxygen delivery is actually enhanced by the embedding in this case. 

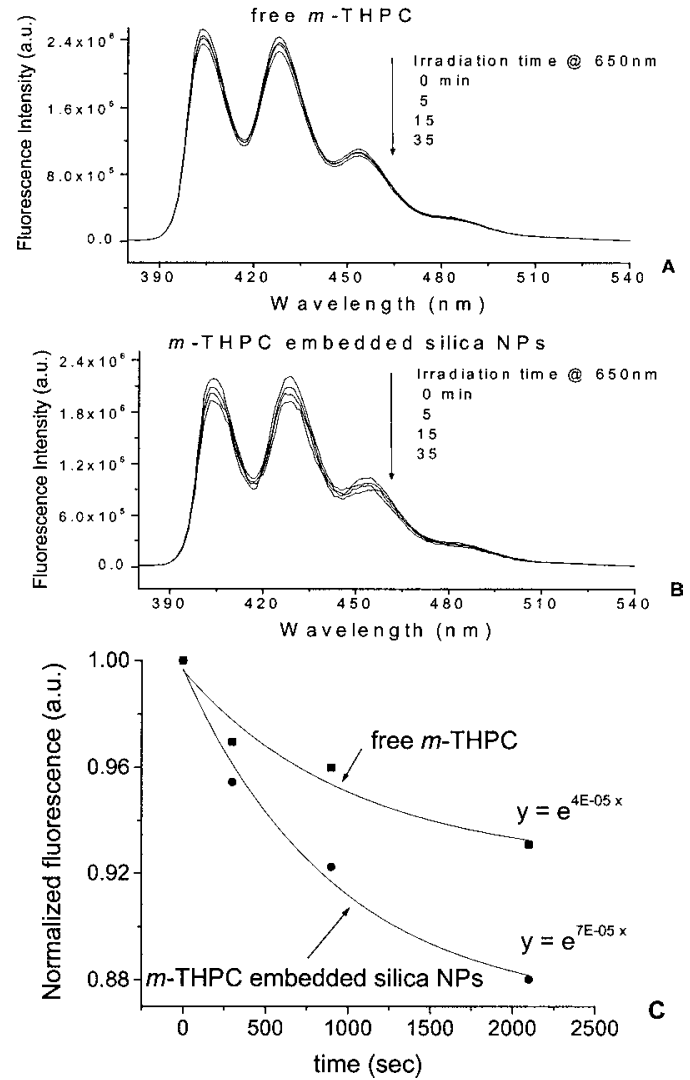

Figure 4. Fluorescence spectra after irradiation at $650 \mathrm{~nm}$ for 5,15 , and 35 min for the mixtures of (A) free $m$-THPC with ADPA, (B) $m$-THPC embedded amine-functionalized silica NP with ADPA, and (C) disappearance of ADPA as a function of irradiation at $650 \mathrm{~nm}$ in the above samples. The amounts of $m$-THPC dye in A and B equal to $0.18 \mu M$, as indicated in Fig. 3.

\section{Absorption from solutions of $\boldsymbol{m}$-THPC}

The absorption spectra of $m$-THPC at different $\mathrm{pH}$ values (Fig. 5) exhibit a strong Soret band near $400 \mathrm{~nm}$ and a weaker Q band between 600 and $700 \mathrm{~nm}$, which is similar to other Chlorin derivatives (30). A very weak band is obtained around $500 \mathrm{~nm}$. The absorption band at $650 \mathrm{~nm}$ is found, in this study, to increase progressively with increasing $\mathrm{pH}$ from 3.44 to 11.65 , whereas the change was almost indiscernible within the experimental error for the $\mathrm{pH}$ range of $6.91-10.18$, in which the background absorbance intensity shifts less than 0.025 (Fig. 5). This observation agrees well with a previous finding, in which no absorption changes were found within the $\mathrm{pH}$ range $6-9$ (24).

\section{Fluorescence from solutions of $m$-THPC vs suspensions of silica NP embedded with $m$-THPC}

Free $m$-THPC has an extremely weak fluorescence in PBS solutions with $\mathrm{pH} 1-10$, because of its lipophilic character. In methanol-PBS solutions, emissions of $m$-THPC are usually detected in the range $630-750 \mathrm{~nm}$, with a peak at $653 \mathrm{~nm}$ (24). For pure $m$-THPC dissolved in ethanol-water (50:50 vol $/ \mathrm{vol})$ and $m$-THPC embedded in silica NP suspended in ethanol-water (50:50 vol/vol), emission intensity was recorded for $\mathrm{pH}$ values in the range 3.44-11.65, as shown in Fig. 6. Here, we found no significant variations in the spectral position or the shape of the

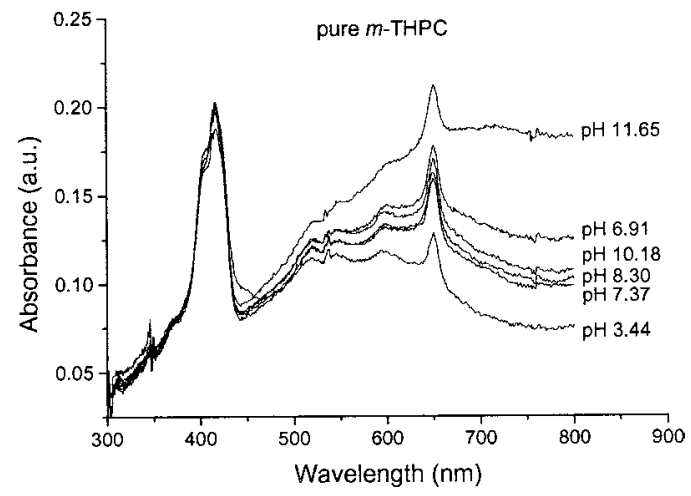

Figure 5. Absorption spectra of $m$-THPC $(2 \mu M)$ dissolved in solvent mixtures consisting of equal amounts of ethanol and PBS at different $\mathrm{pH}$ values.

emission spectra. For pure $m$-THPC solution, the highest emission intensity was observed at $\mathrm{pH}$ 7.37, and the lowest emission intensity was seen at $\mathrm{pH} 11.65$, and there was an indiscernible change, within the experimental error, at $\mathrm{pH}$ values 6.91-10.18. For silica-embedded $m$-THPC, there was also no significant $\mathrm{pH}$ induced decrease in the $\mathrm{pH}$ range 6.91-10.18; however, for silicaembedded $m$-THPC, the highest emission intensity was observed at $\mathrm{pH}$ 3.44. This could be because of the presence of amine groups in the matrix, which may have modified the microstructure of the matrix resulting in a higher local $\mathrm{pH}$ value.
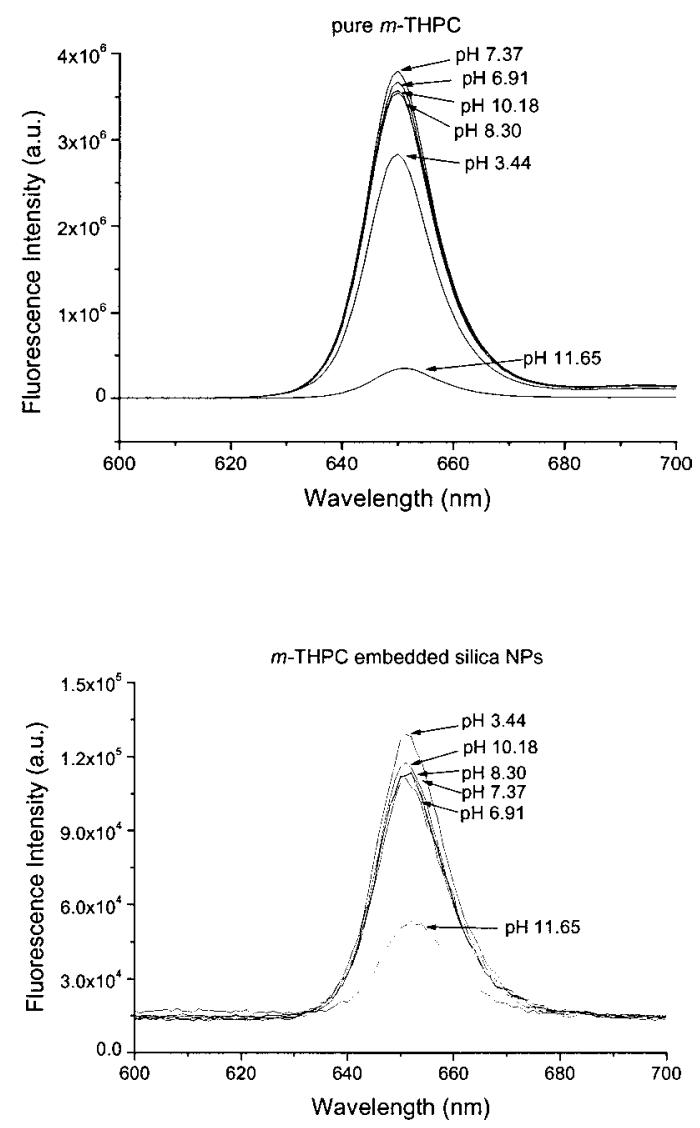

Figure 6. Effect of $\mathrm{pH}$ on the $m$-THPC fluorescence intensity in solution (top) and silica matrix (bottom). 


\section{CONCLUSIONS}

Our results demonstrate the successful embedding of $m$-THPC in amine-functionalized silica NP prepared by a sol-gel approach, the resulting NP platforms only deliver singlet oxygen for PDT while conserving the embedded PS. In addition, we have determined that the exact reaction rate constant with ADPA for free $m$-THPC and $m$-THPC embedded in silica NP is $2.7 \times 10^{8} \mathrm{M}^{-1} \mathrm{~s}^{-1}$ and $4.8 \times 10^{8}$ $M^{-1} \mathrm{~s}^{-1}$, respectively, our observation suggests singlet oxygen production from $m$-THPC embedded in silica NP exceeds that of free $m$-THPC. Absorption spectra of $m$-THPC at different $\mathrm{pH}$ lost most of their resolution, especially in extreme $\mathrm{pHs}$ such as $\mathrm{pH} 3.44$ and $\mathrm{pH}$ 11.65. However, the change was almost indiscernible within the experimental error for the $\mathrm{pH}$ range of $6.91-10.18$, it is unlikely that any protonation or change in lipophilicity will occur within physiological $\mathrm{pH}$ conditions. Furthermore, there is no $\mathrm{pH}$ induced decrease in the fluorescence of silica NP embedded with $m$-THPC in the $\mathrm{pH}$ range 6.91-10.18. The $\mathrm{pH}$ dependence of selective retention, intracellular localization and cellular uptake of $m$-THPC has been discussed recently (26), such a decrease might have affected photodynamic performance as far as the photophysical properties alone are concerned. Because the silica surface is terminated by silanol or amine groups (or both) that can react with various coupling agents to covalently attach specific ligands to these NP, this approach opens the door towards design and synthesis of PS-embedded nanoplatforms, which can be used for the delivery of PDT PS to target cells via antibody-antigen recognition.

Acknowledgements-This study has been supported by National Institutes of Health grant 2R01-GM50300-04A1 and by NCI Contract N01-CO37123. We also thank Jiong Yang for his excellent technical support.

\section{REFERENCES}

1. Levy, J. G. and M. Obochi (1996) New applications in photodynamic therapy introduction. Photochem. Photobiol. 64, 737-739.

2. Dougherty, T. J., C. J. Gomer, B. W. Henderson, G. Jori, D. Kessel, M. Korbelik, J. Moan and Q. Peng (1998) Photodynamic therapy. J. Natl. Cancer Inst. 90, 889-905.

3. Fuchs, J. and J. Thiele (1998) The role of oxygen in cutaneous photodynamic therapy. Free Radic. Biol. Med. 24, 835-847.

4. Oleinick, N. L. and H. H. Evans (1998) The photobiology of photodynamic therapy: cellular targets and mechanisms. Radiat. Res. 150, S146-S156.

5. Popovic, E. A., A. H. Kaye and J. S. Hill (1996) Photodynamic therapy of brain tumors. J. Clin. Laser Med. Surg. 14, 251-261.

6. Jori J. (1996) Tumour photosensitizers: approaches to enhance the selectivity and efficiency of photodynamic therapy. J. Photochem. Photobiol. B: Biol. 36, 87-93.

7. Konan, Y. N., R. Gurny and E. Allemann (2002) State of the art in the delivery of photosensitizers for photodynamic therapy. J. Photochem. Photobiol. B: Biol. 66, 89-106.

8. Leroux, J. C., E. Allemann, F. De Jaeghere, E. Doelker and R. Gurny (1996) Biodegradable nanoparticles from sustained release formulations to improved site specific drug delivery. J. Control. Release 39, 339-350.

9. Savellano, M. D. and T. Hasan (2003) Targeting cells that overexpress the epidermal growth factor receptor with polyethylene glycolated BPD verteporfin photosensitizer immunoconjugates. Photochem. Photobiol. 77, 431-439.

10. Monson, E., M. Brasuel, M. Philbert and R. Kopelman (2003) PEBBLE nanosensors for in vitro bioanalysis. In Biomedical Photonics
Handbook, (Edited by T. Vo-Dinh), pp. 59.1-59.14. CRC Press, Boca Raton, FL.

11. Kopelman, R. (2000) Biocompatible probes measure intracellular activity. Biophotonics Int. 7, 22-24.

12. Bergy, E. J., L. Levy, X. P. Wang, L. J. Krebs, M. Lal, K. S. Kim, S. Pakatchi, C. Liebow and P. N. Prasad (2002) DC magnetic field induced magnetocytolysis of cancer cells targeted by LH-RH magnetic nanoparticles in vitro. Biomed. Microdevices 4, 293-299.

13. Levy, L., Y. Sahoo, K. S. Kim, E. J. Bergey and P. N. Prasad (2002) Nanochemistry: synthesis and characterization of multifunctional nanoclinics for biological applications. Chem. Mater. 14, 3715-3721.

14. Lipson, R. L., E. J. Blades and A. M. Olsen (1961) The use of a derivative of hematoporphyrin in tumor detection. J. Natl. Cancer Inst. 26, 1-11.

15. Dougherty, T. J. (1987) Photosensitizers, therapy and detection of malignant tumors. Photochem. Photobiol. 45, 879-889.

16. D. Kessel (1986) Photosensitization with derivatives of hematoporphyrin. Int. J. Radiat. Biol. 49, 901-907.

17. D. Kessel (1986) Sites of photosensitization by derivatives of hematoporphyrin. Photochem. Photobiol. 44, 489-493.

18. Hadjur, C., N. Lange, J. Rebstein, P. Monnier, H. van den Bergh and G. Wagnieres (1998) Spectroscopic studies of photobleaching and photoproduct formation of meta(tetrahydroxyphenyl)chlorin ( $m$-THPC) used in photodynamic therapy. The production of singlet oxygen by $m$ THPC. J. Photochem. Photobiol. B.: Biol. 45, 170-178.

19. Datta, A., A. Dube, B. Jain, A. Tiwari and P. K. Gupta (2002) The effect of $\mathrm{pH}$ and surfactant on the aggregation behavior of Chlroin p6: a fluorescence spectroscopic study. Photochem. Photobiol. 75, 488-494.

20. Lindig, B. A., and M. A. J. Rodgers (1981) Rate parameters for the quenching of singlet oxygen by water-soluble and lipid-soluble substrates in aqueous and micellar systems. Photochem. Photobiol. 33, 627-634.

21. Zimmermann, A., M. Ritsch-Marte and H. Kostron (2002) In vitro investigation on the $\mathrm{pH}$ dependence of the adsorption and fluorescence properties of the photosensitizer mTHPC. Photochem. Photobiol. 75, 335-338.

22. Moreno, M. J., E. Monson, R. G. Reddy, A. Rehemtulla, B. D. Ross, M. Philbert, R. J. Schneider and R. Kopelman (2003) Production of singlet oxygen by $\mathrm{Ru}\left(\mathrm{dpp}\left(\mathrm{SO}_{3}\right)_{2}\right)_{3}$ incorporated in polyacrylamide PEBBLEs. Sens. Actuators B: Chem. 90, 82-89

23. Hadjur, C., A. Jeunet and P. Jardon (1994) Photosensitization by hypericin: ESR evidence for singlet oxygen and superoxide anion radicals formation in an invitro model. J. Photochem. Photobiol. B: Biol. 26, 67-74.

24. Lindig, B. A., M. A. J. Rodgers and A. P. Schaap (1980) Determination of the lifetime of singlet oxygen in water-d2 using 9,10-anthracenedipropionic acid, a water-soluble probe. J. Am. Chem. Soc. 102, 55905593.

25. Merkel, P. B. and D. R. Kearns (1975) Rate constant for the reaction between 1,3-diphenylisobenzofuran and singlet oxygen. J. Am. Chem. Soc. 97, 462-463.

26. Cunderlikova, B., E. G. Bjorklund, E. O. Pettersen and J. Moan (2001) pH-dependent spectral properties of HpIX, TPPS ${ }_{2 \mathrm{a}}, m \mathrm{THPP}$ and mTHPC. Photochem. Photobiol. 74, 246-252.

27. Phillips, J. N. (1960) The ionization and coordination behaviour of porphyrins. Rev. Pure Appl. Chem. 10, 35-60.

28. Zahir, K. O. and A. J. Haim (1992) Yields of singlet dioxygen produced by the reaction between the excited state of tris(bipyridine)ruthenium(II) and triplet dioxygen in various solvents. J. Photochem. Photobiol. A: Chem. 63, 167-172.

29. Roy, I., T. Y. Ohulchanskyy, H. E. Pudavar, E. J. Bergey, A. R. Oseroff, J. Morgan, T. J. Dougherty and P. N. Prasad (2003) Ceramicbased nanoparticles entrapping water-insoluble photosensitizing anticancer drugs: a novel drug-carrier system for photodynamic therapy. J. Am. Chem. Soc. 125, 7860-7865.

30. Bohmer, R. M. and G. Morstyn (1985) Uptake of hematoporphyrin derivative by normal and malignant cells: effect of serum, $\mathrm{pH}$, temperature and cell size. Cancer Res. 50, 7876-7881. 